\title{
MMMI High Stakes for the Health of Sexual and Gender Minority Patients of Color
}

Judy Y. Tan, Ph.D. ${ }^{2}$, Arshiya A. Baig, M.D., M.P. $H^{2}$, and Marshall H. Chin, M.D., M.P. $H^{2}$

'Division of Prevention Science, Department of Medicine, University of California San Francisco, San Francisco, CA, USA; ${ }^{2}$ Department of Medicine, University of Chicago, Chicago, IL, USA.

As clinicians, educators, and researchers, our ability to provide the best possible care to our patients who are sexual and gender minority (SGM) people of color is increasingly challenged. Relative to the general population, SGM patients often have worse health outcomes, and among SGM patients, racial and ethnic minorities are particularly vulnerable. Healthcare policies proposed by the current administration, along with an increasingly hostile and dangerous social climate, have the potential to seriously harm SGM patients of color. In this paper, we discuss these key policy issues impacting the health of SGM patients of color. We then suggest questions for clinicians to consider to help them decide which advocacy activities are right for them, recommending self-examination, skills development, and political action. We end by outlining concrete, actionable steps to advocate for SGM patients of color in patient care, healthcare organizations, medical education, research, and public policy.

J Gen Intern Med 32(12): 1390-5

DOI: $10.1007 / \mathrm{s} 11606-017-4138-3$

(c) Society of General Internal Medicine 2017 racial and ethnic minority status. ${ }^{3,4}$ Under President Trump's administration, SGM who are also racial/ethnic minorities face new threats to their health and safety due to attacks on protective health and social legislation and the enactment of deleterious policies. ${ }^{5}$ Health disparities will worsen without our timely, concerted, and committed advocacy efforts.

Here, we discuss harmful proposed health policies that would negatively affect SGM patients of color. ${ }^{6}$ We explain the health impact of discriminatory policies that create an increasingly hostile and dangerous environment for sexual and gender minorities, racial/ethnic minorities, and individuals who share both sets of identities. We provide concrete, actionable advocacy steps for clinicians, educators, and researchers, outlining a set of questions to consider as they decide which advocacy activities are right for them. We end by discussing specific advocacy actions for patient care, healthcare organization transformation, medical education, and public policy that can enhance the health of SGM patients of color during this critical and challenging time.

\section{ATTACKS ON NEW HEALTHCARE GAINS AND LEGAL PROTECTIONS FOR SGM INDIVIDUALS}

As clinicians, educators, and researchers, we promise to heal, cure, and otherwise improve the health of individuals with the utmost respect for human life. Since the 2016 U.S. presidential election, our pledge has taken on new meaning, as we grapple with the impact of unprecedented legislative challenges and a changing social climate on the health of some of the most vulnerable patient populations. Sexual and gender minority (SGM) patients, including those who are lesbian, gay, bisexual, transgender, or queer (LGBTQ), continually face discrimination and violence across healthcare, employment, housing, and education settings. ${ }^{1}$ Relative to the general population, SGM individuals are often sicker and poorer, while facing tremendous barriers in accessing quality medical care and services. ${ }^{1,2}$ SGM individuals who also identify as racial/ethnic minorities may be even more vulnerable, because the barriers, discrimination, and violence they face as SGM intersect with and are often compounded by those unique to immigration and/or

Received January 12, 2017

Revised May 9, 2017

Accepted July 7, 2017

Published online August 10, 2017
Under the Affordable Care Act (ACA), the proportion of uninsured adult Americans decreased from $20 \%$ to $12 \%$ between 2010 and $2016 .^{7}$ The ACA has clear flaws that need addressing, such as stabilization of the health exchange marketplaces, but attempts to repeal the ACA would reverse gains, increase the number of uninsured, and cost lives. ${ }^{8,9}$ For example, the proposed American Health Care Act (AHCA) would have increased the number of uninsured to 24 million by 2026, due largely to states discontinuing their expansion of Medicaid eligibility. ${ }^{6}$

The ACA's Section 1557 is a federal civil rights law that bans discrimination based on sex, which the Department of Health and Human Services (HHS) interpreted to include discrimination based on gender identity (i.e., citing gender identity as a basis for denying coverage for healthcare services related to gender transition) for health programs or activities that receive federal financial assistance. ${ }^{10,11}$ Prior to the ACA, being transgender was considered by many private insurance carriers to be a pre-existing condition. ${ }^{10}$ Since the ACA, the Nondiscrimination in Health Programs and Activities rule 
proposed by the HHS specifically prohibits medically indicated sex-specific healthcare (e.g., cervical cancer screening in female at birth) from being denied or limited based on current gender identity (e.g., individual's identification as a transgender man). ${ }^{11}$ Repealing these protective measures under the ACA would compromise healthcare for thousands of SGM individuals.

Public policy affects the health of SGM patients not only via healthcare access, but also through attacks on civil liberties. ${ }^{12}$ Threats to remove legal protection for marriage equality, for example, would decrease access to state and federal healthcare, increase taxes, and diminish social security and veterans' benefits to same-sex partnerships. ${ }^{12}$ Some Cabinet members have supported legislation opposing same-sex marriage, workplace discrimination protection for SGM people, and inclusion of sexual orientation and gender identity in hate crime legislation. ${ }^{13,14}$ The Texas House Bill 3859 would allow foster care providers to refuse to place children with non-Christians and same-sex couples. $^{15}$

\section{ATTACKS ON NEW HEALTHCARE GAINS AND LEGAL PROTECTIONS FOR SGM PATIENTS OF COLOR}

SGM patients who are racial/ethnic minorities are at particularly high risk for worsening health disparities if protections are repealed. The personal experiences of people with multiple intersecting social identities (e.g., Asian-American, lesbian, undocumented status) are shaped by interlocking systems of social inequality (e.g., racism, heterosexism, xenophobia). ${ }^{16}$ Thus, SGM patients of color frequently have worse health outcomes than either white SGM or heterosexual patients of color. For example, LGB Latinos/Hispanics have especially high rates of alcohol abuse, ${ }^{17}$ cigarette smoking, sexually transmitted infections, and mental health problems. ${ }^{18}$ Prior to the ACA, LGBTQ racial/ethnic minorities showed lower rates of insurance coverage, less regular healthcare access, and greater reliance on emergency services relative to LGBTQ whites. ${ }^{19}$ Since passage of the ACA, uninsured rates have declined across racial, ethnic, age, and income groups. ${ }^{20} \mathrm{Un}$ insured rates dropped from $21 \%$ to $13 \%$ between 2013 and 2016 among African Americans, and from 36\% to 19\% among Latinos during the same period. ${ }^{21}$ Removing healthcare protections is regressive for SGM patients of color and would widen health disparities of the most vulnerable who depend on Medicaid and the ACA. ${ }^{5}$

Anti-immigration policies under the Trump presidency undermine the health of SGM patients of color who may avoid seeking healthcare and public assistance due to fear of deportation. ${ }^{22-25}$ Among those who seek care, some may hesitate to give personal information such as their sexual orientation or gender identity to healthcare and social service providers. ${ }^{23-25}$ A lack of legal documentation status adversely affects health. Undocumented transgender Latinas are at higher risk for HIV infection due to worse healthcare access, housing, and employment. $^{26}$

SGM patients of color are targets of an increasingly dangerous and hostile environment. At least eight transgender women of color have been murdered since the beginning of $2017 .^{27,28}$ Following President Trump's election, reports soared of random incidents of harassment and intimidation directed at SGM people, people of color, and immigrants. $^{29}$

\section{WHAT CLINICIANS, EDUCATORS, AND RESEARCHERS CAN DO TO ADVOCATE FOR SGM PATIENTS OF COLOR}

Our ability to provide quality healthcare to an already underserved patient population is challenged as access to healthcare and other civil liberties of SGM patients of color are threatened. However, we can do much to improve the health of our patients. ${ }^{30-33}$ We offer advice to clinicians to help them decide what advocacy activities are right for them (Table 1). ${ }^{34,35} \mathrm{We}$ also include a compendium of actionable items for advocacy in patient care, healthcare organization, training and mentoring, and policy (Table 2). ${ }^{34}$

\section{ADVOCACY TO IMPROVE THE HEALTH OF SGM PATIENTS OF COLOR}

Advocacy may initially seem like an alien or intimidating concept to the clinician. ${ }^{42}$ However, our experience shows that virtually all clinicians believe it is their responsibility to advocate for their individual patients. Many clinicians eventually recognize how much they can improve the health of their patients through advocacy at the organizational and policy levels. ${ }^{34}$ Clinicians have a unique understanding of how policies impact patients, and are respected for their knowledge and experience. ${ }^{34}$

We recommend a process of self-examination in which you prioritize specific advocacy issues based on their personal meaning and importance, and your opportunity to impact them (Table 1). ${ }^{34}$ Decide which domain or domains of action are right for you in patient care, your healthcare organization or professional society, training and mentoring, or public policy. We can all benefit from developing advocacy skills in writing, speaking, teaching, mentoring, and political organizing. Learn the legislative process and specific policy issues. Understand the social determinants of equity and where you can intervene. Develop leadership skills and leverage your experience as a clinician to change policy. Voice your opinions and learn how to take collective action with organizations and coalitions. Stay current about policy issues, and understand thoughtful views and ideas across the political spectrum. 
Table 1 Advice to Clinicians Considering Advocacy to Improve the Health of Sexual and Gender Minority (SGM) Patients of Color

\begin{tabular}{|c|c|}
\hline Domains & Examples of Clinician Actions \\
\hline Self-Examination ${ }^{34}$ & $\begin{array}{l}\text { Prioritize specific issues based on personal meaning, importance, and opportunity to impact. } \\
\text { Choose domain(s) of action: Patient Care, Healthcare Organization, Training and Mentoring, Policy. } \\
\text { Recognize that your and your colleagues' clinical, teaching, and research expertise are powerful tools } \\
\text { for political action and changing organizational and public policy. }\end{array}$ \\
\hline Skills Development $^{34,35}$ & $\begin{array}{l}\text { Develop skills in writing, speaking, teaching, mentoring, organizing, and advocating. Learn about health } \\
\text { disparities, and understand the legislative process and specific policy issues. } \\
\text { Understand models of social determinants of equity, such as that of Camara Phyllis Jones, and } \\
\text { intervention points: } \\
\text { - Decision-making structures (who, what, when, where) } \\
\text { - Written policies } \\
\text { - Unwritten practices and norms } \\
\text { - Values driving decisions } \\
\text { Use your experience as a clinician and specific patient examples to tell the story of why SGM patients } \\
\text { of color need health insurance coverage and access to high-quality, culturally competent care and services. } \\
\text { Develop leadership skills in coalition building. Leverage political capital of coalitions to move policymakers } \\
\text { at the local, state, and national levels. } \\
\text { Develop leadership, management, and implementation skills to transform clinics and organizations to deliver } \\
\text { high-quality, culturally competent care. } \\
\text { Learn how to train students. physicians. educators, and researchers in advocacy skills. }\end{array}$ \\
\hline Political Action ${ }^{34}$ & $\begin{array}{l}\text { - Vote, call, and/or meet legislators. } \\
\text { - Sign petitions and position statements. } \\
\text { - Write commentaries. } \\
\text { - Give talks. } \\
\text { - Communicate through social media. } \\
\text { Take collective action. } \\
\text { - Participate in organizational advocacy, partnerships, and coalitions, both with organizations already } \\
\text { committed to health equity and with influential organizations that should expand their advocacy for } \\
\text { health equity. } \\
\text { - Organize coalitions of organizations interested in expanding health insurance coverage and high-quality, } \\
\text { culturally competent care to SGM people of color. } \\
\text { - March, demonstrate, and rally (e.g., Pride Parade, White Coats for Black Lives, March for Science). } \\
\text { Volunteer for community- and statewide advisory boards working on healthcare reform and/or health } \\
\text { disparity issues. } \\
\text { Track policy changes regarding discrimination, health disparities, and health policy via sources such as } \\
\text { Health Affairs Blog (http://healthaffairs.org/blog/) and Kaiser Family Foundation (http://kff.org/). Read } \\
\text { conservative, moderate, and liberal news and commentary sources. }\end{array}$ \\
\hline
\end{tabular}

\section{ACTIONABLE ADVOCACY}

Patient Care. Even the most experienced clinicians can often improve their ability to deliver culturally competent, high-quality healthcare for SGM patients of color (Table 2). Show your willingness to listen to their stories, allow them to self-identify, and encourage them to participate in healthcare decision making. ${ }^{36}$ Realize that patients' lack of trust stems from actual negative experiences and a legacy of discrimination. ${ }^{23,25,43}$ Similarly, providers should be aware that great diversity exists among SGM patients of color. For example, Asian-American and Pacific Islander sexual and gender minorities represent a group that varies tremendously in income, employment, education, English proficiency, and health status. Review mental health status and needs for social services, and be aware of SGMspecific services.

Healthcare Organization. Clinics can transform their culture and structure to provide culturally competent care to SGM patients of color. ${ }^{31}$ For patients with limited English proficiency, clinics must provide access to medical interpreters and materials in various languages and dialects. Clinics can train clinicians and staff to call patients by their preferred names and pronouns. Electronic health systems can be programmed to collect patient data on race, ethnicity, sex assigned at birth, sexual orientation, and gender identity; use these data to inform clinic practice, identify health disparities, and guide quality improvement efforts. ${ }^{31}$ Institute screening and offer referrals for SGM patients of color who suffer from trauma, physical and sexual violence, and drug and alcohol abuse. Organize peer support groups. ${ }^{44}$

Training and Mentoring. SGM patients of color have frequently reported negative attitudes among healthcare workers and lack of skills in SGM health. ${ }^{23}$ Medical educators can act as role models, individualizing care for SGM patients of color and taking opportunities to teach students about clinical, cultural, and communication issues. ${ }^{34,35}$

Policy. Realize that your clinical, research, and teaching expertise are powerful tools for changing institutional practices and public policy toward equitable healthcare. ${ }^{34}$ Clinicians can build or join coalitions, or raise awareness to improve upon the ACA and keep protections for SGM patients of color to ensure that the number of uninsured will not rise. ${ }^{34}$ 
Table 2 Actionable Items to Improve the Health of Sexual and Gender Minority (SGM) Patients of Color for Patient Care, Healthcare Organization, Training and Mentoring, and Policy




Clinicians can protest legislation that would harm the health of SGM patients of color by restricting access to healthcare, such as repealing Section 1557 of the ACA or withholding funding from Planned Parenthood clinics that provide essential preventive and primary care to many low-income and racial/ ethnic minority patients. ${ }^{45}$

E-mail your legislators and support policies that ensure the civil rights of SGM and racial/ethnic minority adults and children. Protest the removal of gender-matching bathroom access that undermines health and safety. ${ }^{46}$ Gender-matching bathroom access could be especially important for SGM students of color, who experience harassment, school-based victimization such as being threatened or injured with a weapon, ${ }^{47}$ and physical and sexual assault from peers and even teachers. ${ }^{1}$ Protest antiimmigration policies that pose barriers to healthcare access among SGM and racial/ethnic minority patients. ${ }^{25}$

Advocate for research funding for SGM and racial/ethnic minority health. Support data collection disaggregated by SGM and racial/ethnic minority status. ${ }^{30}$ Be vigilant for efforts to eliminate data sources on the diversity of SGM patients of color, such as the removal of sexual orientation and gender identity categories from proposed versions of the U.S. Census Bureau, the American Community Survey, and two Department of Health and Human Services surveys on the health of older adults. $^{48}$

The stakes are higher than ever for closing the healthcare gap for our SGM patients of color. Our core role and great privilege is to care and advocate for our individual patients. However, proposed policy changes pose dangerous threats to the most vulnerable and already underserved patients, and we can do much within and beyond the walls of our clinics and academic institutions to support our patients. Many impactful actions along the spectrum of advocacy may be right for you. The more skills and experience one develops in advocacy, the more comfortable one feels and the better one gets at it. Our obligation to our patients includes advocating for them when their health and well-being are threatened. Policies that would harm the health of vulnerable people and create hostile environments are a concern for everyone, not just SGM patients of color.

Acknowledgments: We would like to thank Alison El Ayadi, the KScholars Program, Daryl A. Mangosing, and our many colleagues from UCSF for their comments on versions of this manuscript, and our many colleagues at the University of Chicago for their review of earlier versions of the tables.

Corresponding Author: Judy Y. Tan, Ph.D.; Division of Prevention Science, Department of MedicineUniversity of California San Francisco, 550 16th Street, Box 0886, San Francisco, CA 94158, USA (e-mail: Judy.tan@ucsf.edu).

\section{Compliance with Ethical Standards:}

Conflict of Interest: The authors declare that they have no conflict of interest.

\section{REFERENCES}

1. Grant $J$, Mottet L, Tanis $J$, Harrison J, Herman J, Keisling M. Injustice at every turn: A report of the national transgender discrimination survey. Washington DC: National Center for Transgender Equality and National Gay and Lesbian Task Force; 2011. http://www. thetaskforce.org/static_html/downloads/reports/reports/ntds_full.pdf. Accessed April 24, 2017.

2. Mayer KH, Bradford JB, Makadon HJ, Stall R, Goldhammer H, Landers S. Sexual and gender minority health: What we know and what needs to be done. Am J Public Health 2008;98(6):989.

3. Crenshaw K. Mapping the margins: Intersectionality, identity politics, and violence against women of color. Stanford Law Rev 1991:1241-1299.

4. Ng HH. Intersectionality and shared decision making in LGBTQ health. LGBT Health 2016;3(5):325-326.

5. Byne w. Sustaining progress toward LGBT health equity: A time for vigilance, advocacy, and scientific inquiry. LGBT Health 2017;4(1):1-3.

6. Congressional Budget Office. Budget reconciliation recommendations of the House Committees on Ways and Means and Energy and Commerce: American Health Care Act. March 13, 2017. Available from: https://www. cbo.gov/system/files/115th-congress-2017-2018/costestimate/ americanhealthcareact.pdf. Accessed April 30, 2017.

7. Collins S, Gunja M, Doty M, Beutel S. Americans' experiences with ACA marketplace and Medicaid coverage: Access to care and satisfaction. The Commonwealth Fund. May 25, 2016. Available from: http://www. commonwealthfund.org/publications/issue-briefs/2016/may/acatracking-survey-access-to-care-and-satisfaction. Accessed April 30, 2017.

8. Himmelstein DU, Woolhandler S. Trumpcare or Transformation. Am J Public Health 2017;107(5):660-661.

9. Gonzales G, Henning-Smith C. The Affordable Care Act and health insurance coverage for lesbian, gay, and bisexual adults: Analysis of the behavioral risk factor surveillance system. LGBT Health 2017;4(1):62-67.

10. Baker KE. The Future of Transgender Coverage. [Published online April 5, 2017]. N Engl J Med 2017. DOI: 10.1056/NEJMp1702427

11. Office for Civil Rights of the US Department of Health and Human Services. Nondiscrimination in health programs and activities proposed rule. Web site. https://www.hhs.gov/civil-rights/for-individuals/section1557/nondiscrimination-health-programs-and-activities-proposed-rule/ index.html. Updated 2012. Accessed May 1, 2017.

12. Perone AK. Health implications of the Supreme Court's Obergefell vs. Hodges marriage equality decision. LGBT Health 2015;2(3): 196-199.

13. Singh S, Durso L. Attorney General nominee Jeff Sessions threatens basic LGBT rights. Center for American Progress. January 6, 2017. Available from: https://www.americanprogress.org/issues/lgbt/news/ 2017/01/06/296093/attorney-general-nominee-B -sessions-threatensbasic-lgbt-rights/. Accessed April 30, 2017.

14. Singh S, Durso L. Tom Price would jeopardize LGBT people's health and wellness. Center for American Progress. January 18, 2017. Available from: https://www.americanprogress.org/issues/lgbt/news/2017/01/ 18/296672/tom-price-would-jeopardize-lgbt-peoples-health-and-wellness/. Accessed April 30, 2017.

15. House Bill 3859. Texas Legislature Online Web site. http://www.legis. state.tx.us/BillLookup/History.aspx?LegSess=85R\&Bill=HB3859. Updated 2017. Accessed April 30, 2017.

16. Bowleg L. Intersectionality: an underutilized but essential theoretical framework for social psychology. In: The Palgrave Handbook of Critical Social Psychology. Springer; 2017:507-529.

17. Krehely J. How to close the LGBT health disparities gap: Disparities by race and ethnicity. Center for American Progress. December 21, 2009. Available from: https://cdn.americanprogress.org/wp-content/uploads/issues/ 2009/12/pdf/lgbt_health_disparities_race.pdf. Accessed April 30, 2017.

18. Martinez O, Lee JH, Bandiera F, Santamaria EK, Levine EC, Operario D. Sexual and behavioral health disparities among sexual minority Hispanics/Latinos: Findings from the National Health and Nutrition Examination Survey, 2001-2014. Am J Prev Med. 2017.

19. Macapagal K, Bhatia R, Greene GJ. Differences in healthcare access, use, and experiences within a community sample of racially diverse lesbian, gay, bisexual, transgender, and questioning emerging adults. LGBT Health 2016;3(6):434-442.

20. Collins S, Gunja M, Doty M, Beutel S. How the Affordable Care Act has improved Americans' ability to buy health insurance on their own. The Commonwealth Fund. February 1, 2017. Available from: http://www. 
commonwealthfund.org/publications/issue-briefs/2017/feb/how-theaca-has-improved-ability-to-buy-insurance. Accessed April 30, 2017.

21. Doty M, Gunja M, Collins S, Beutel S. Latinos and Blacks have made major gains under the Affordable Care Act, but inequalities remain. The Commonwealth Fund. August 18, 2016; To the Point. Available from: http://www.commonwealthfund.org/publications/blog/2016/aug/latinos-blacks-major-gains-under-aca. Accessed April 30, 2017.

22. Hacker K, Anies M, Folb BL, Zallman L. Barriers to health care for undocumented immigrants: A literature review. Risk Manag Healthc Policy 2015;8:175-183.

23. Wilson PA, Yoshikawa H. Improving access to health care among African-American, Asian and Pacific Islander, and Latino lesbian, gay, and bisexual populations. In: The Health of Sexual Minorities. Springer; 2007:607-637.

24. Kaufmann G. Why immigrants in California are canceling their food stamps. The Nation. March 17, 2017. Available from: https://www. thenation.com/article/why-immigrants-in-california-are-canceling-theirfood-stamps/. Accessed April 30, 2017.

25. Gostin LO, Cathaoir KEÓ. Presidential immigration policies: Endangering health and well-being? JAMA 2017;317(16):1617-1618.

26. Palazzolo SL, Yamanis TJ, De Jesus M, Maguire-Marshall M, Barker SL. Documentation status as a contextual determinant of HIV risk among young transgender Latinas. LGBT Health 2016;3(2):132-138.

27. Selk A. Seven transgender women have been killed this year. Democrats want Jeff Sessions to investigate. Washington Post. March 16, 2017 Available from: https://www.washingtonpost.com/news/powerpost/wp/ 2017/03/16/seven-transgender-women-have-been-killed-this-yeardemocrats-want-jeff-sessions-to-investigate/?utm_term=.2bab909510ac. Accessed April 1, 2017.

28. Torres A, Livingston L. Miami-Dade detectives investigate transgender woman's fatal shooting. ABC News. April 22, 2017. Available from: http://www.local10.com/news/crime/miami-dade-detectives-investigate-transgender-womans-murder. Accessed April 30, 2017.

29. Southern Poverty Law Center. More than 400 incidents of hateful harassment and intimidation since the election. Southern Poverty Law Center. November 15, 2016. Available from: https://www.splcenter.org/ hatewatch/2016/11/15/update-more-400-incidents-hateful-harassment-and-intimidation-election. Accessed May 1, 2017.

30. Tan JY, Xu LJ, Lopez FY, et al. Shared decision making among clinicians and Asian American and Pacific Islander sexual and gender minorities: An intersectional approach to address a critical care gap. LGBT Health 2016;3(5):327-334.

31. DeMeester RH, Lopez FY, Moore JE, Cook SC, Chin MH. A model of organizational context and shared decision making: Application to LGBT racial and ethnic minority patients. J Gen Intern Med 2016;31(6):651-662.

32. Ruger JP. Health and social justice. Lancet 2004;364(9439):1075-1080.

33. Baig AA, Lopez FY, DeMeester RH, Jia JL, Peek ME, Vela MB. Addressing barriers to shared decision making among Latino LGBTg patients and healthcare providers in clinical settings. LGBT Health 2016;3(5):335-341.
34. Earnest MA, Wong SL, Federico SG. Perspective: Physician advocacy: What is it and how do we do it? Acad Med 2010;85(1):63-67.

35. Jones CP, Jones CY, Perry GS, Barclay G, Jones CA. Addressing the social determinants of children's health: A cliff analogy. J Health Care Poor Underserved 2009;20(4A):1-12.

36. Peek ME, Lopez FY, Williams HS, et al. Development of a conceptual framework for understanding shared decision making among AfricanAmerican LGBT patients and their clinicians. J Gen Intern Med 2016;31(6):677-687.

37. Cook SC, Gunter KE, Lopez FY. Establishing effective health care partnerships with sexual and gender minority patients: Recommendations for obstetricians and gynecologists. Semin Reprod Med 2017;(in press).

38. Chin MH, Lopez FY, Nathan AG, Cook SC. Improving shared decision making with LGBT racial and ethnic minority patients. J Gen Intern Med 2016;31(6):591-593.

39. Chin MH, Clarke AR, Nocon RS, et al. A roadmap and best practices for organizations to reduce racial and ethnic disparities in health care. J Gen Intern Med 2012;27(8):992-1000.

40. Safer JD, Coleman E, Feldman J, et al. Barriers to healthcare for transgender individuals. Curr Opin Endocrinol Diabetes Obes 2016:23(2):168-171.

41. Chin MH. Creating the business case for achieving health equity. J Gen Intern Med 2016;31(7):792-796.

42. Chin MH. Movement advocacy, personal relationships, and ending health care disparities. J Natl Med Assoc 2017;109(1):33-35.

43. Brenick A, Romano K, Kegler C, Eaton LA. Understanding the influence of stigma and medical mistrust on engagement in routine healthcare among Black women who have sex with women. LGBT Health 2017;4(1):4-10.

44. Holt-Lunstad J, Smith TB, Layton JB. Social relationships and mortality risk: A meta-analytic review. PLoS Med 2010;7(7):e1000316.

45. Eilperin J. Behind closed doors, Trump signs bill allowing states to strip federal family planning funds from abortion providers. Washington Post. April 13, 2017. Available from: https://www.washingtonpost.com/news/ powerpost/wp/2017/04/13/behind-closed-doors-trump-signs-billallowing-states-to-strip-federal-family-planning-dollars-from-abortionproviders/?utm_term=.02de88b215ad. Accessed April 30, 2017.

46. Trotta D. Trump revokes Obama guidelines on transgender bathrooms. Reuters. February 27, 2017. Available from: http://www.reuters.com/ article/us-usa-trump-lgbt-idUSKBN161243. Accessed April 30, 2017.

47. Bouris A, Everett BG, Heath RD, Elsaesser CE, Neilands TB. Effects of victimization and violence on suicidal ideation and behaviors among sexual minority and heterosexual adolescents. LGBT Health 2016;3(2):153-161.

48. Kellman L. No Category for LGBTQ Americans in 2020 Census Proposal. Boston Globe. March 29, 2017. Available from: https://www.bostonglobe. com/news/nation/2017/03/29/the-census-wouldn-count-lgbtq-americans-under-proposal/S5TmzHdVNYEF72P5NXFPpN/story.html. Accessed April 30, 2017. 